\title{
Occupations rurales antiques de la plaine d'Argentan-Mortrée
}

\section{Guy Leclerc}

\section{(2) OpenEdition \\ Journals}

Édition électronique

URL : https://journals.openedition.org/adlfi/3838

ISSN : 2114-0502

Éditeur

Ministère de la Culture

Référence électronique

Guy Leclerc, "Occupations rurales antiques de la plaine d'Argentan-Mortrée » [notice archéologique], ADLFI. Archéologie de la France - Informations [En ligne], Normandie, mis en ligne le 01 mars 2009, consulté le 22 juin 2021. URL : http://journals.openedition.org/adlfi/3838

Ce document a été généré automatiquement le 22 juin 2021.

(c) ministère de la Culture et de la Communication, CNRS 


\section{Occupations rurales antiques de la plaine d'Argentan-Mortrée}

Guy Leclerc 
Date de l'opération : 2009 (PT)

1 L'opération 2009 s'est intéressée au territoire de quatre nouvelles communes situées au sud-ouest de la plaine; trois d'entre-elles sont adossées au massif forestier d'Écouves en limite du bassin sédimentaire.

Quantitativement, le bilan 2009 s'établit à 18 sites inédits répartis ainsi par commune :

3 - Saint-Christophe-le-Jajolet : 2 ;

$4 \quad$ - Vrigny : 6 ;

5 - Fleuré : 5 ;

6 - Sarceaux : 5.

7 Les découvertes concernent majoritairement de petites occurrences peu étendues et peu documentées en surface, sans doute en relation avec un important établissement (vicusou villa)repéré en limite des communes de Vrigny et d'Argentan. Ces petites formations, parfois constituées uniquement de tuiles à rebord, semblent correspondre à de petits bâtiments isolés dotés de murs en matériaux légers et de toitures en dur.

8 La répartition des formations sédimentaires dans cette partie de la plaine n'a pas permis de mettre en évidence un schéma raisonné d'aménagement de l'espace rural antique. Contrairement aux facteurs d'implantation mis en évidence en 2008 en bordure du tronçon de voie Sées-Argentan, l'organisation, vers l'ouest, semble anarchique avec des interdistances très variables entre sites.

9 Un phénomène déjà constaté en 2008, et qui semble récurrent dans la plaine d'Argentan, est l'épandage de matériaux gallo-romains dans de nombreuses parcelles. Concrètement, il se manifeste par la présence en surface de morceaux de tuiles isolés ou dispersés.

Guy LECLERC

\section{AUTEURS}

GUY LECLERC

BEN 